\title{
Erratum to: Severe respiratory symptoms to oxaliplatin infusion: a case report of delayed hypersensitivity reaction
}

Simona Potenza • Guglielmo Nasti •

Alessandro Ottaiano • Amelia Filippelli •

Francesco Rossi • Annalisa Capuano

Published online: 25 February 2010

(C) Springer Science+Business Media, LLC 2010

\section{Erratum to: Invest New Drugs}

\section{DOI 10.1007/s10637-009-9250-8}

The original version of this article unfortunately contained a mistake. The given name and last name of Alessandro Ottaiano was not listed correctly. The correct name is shown here.

The online version of the original article can be found at http://dx.doi. org/10.1007/s10637-009-9250-8.

S. Potenza $(\bowtie) \cdot$ A. Filippelli $\cdot$ F. Rossi $\cdot$ A. Capuano

Section of Pharmacology "L. Donatelli",

Department of Experimental Medicine,

Second University of Naples,

Via Costantinopoli 16,

80138 Naples, Italy

e-mail:simipot@hotmail.it

G. Nasti • A. Ottaiano

Colorectal Department, 'G. Pascale' Foundation,

National Cancer Institute of Naples,

Via M. Semmola,

80131 Naples, Italy 